\title{
The Chlorophyll Biosynthesis and Degradation and Chloroplast Structure in Tomato Yellow Mutant
}

\author{
Mo-zhen Cheng ${ }^{1}$, Hao-nan $\mathrm{Qi}^{1}$, Fu-lei Mo ${ }^{1}$, Jiangang Yao ${ }^{2}$, Lei Zhuang ${ }^{3}$ and He Zhang ${ }^{4}$ \\ ${ }^{1}$ College of Life Sciences, Northeast Agricultural University, China \\ ${ }^{2}$ Yantai Agricultural Science Academy of Shandong Province, China \\ ${ }^{3}$ Harbin Academy of Agricultural Science, China \\ ${ }^{4}$ College of Horticulture and Landscape Architecture, Northeast Agricultural University, China
}

\begin{abstract}
Yellow mutant is an important material for studying chlorophyll biosynthesis, degradation and the genetics and development of chloroplasts. The chlorophyll biosynthesis and degradation pathways of tomato (Solanum lycopersicum) mutant ym (Yellow mutant) and control ZS4 (Zhongshu 4) were studied. Photosynthetic parameters and chlorophyll fluorescence parameters of the variety ym and ZS4 were measured. The results showed that $y m$ was more sensitive than the variety ZS4, while the variety ym has more tolerant to low light. The chloroplasts in ym exhibited onset of degradation compared with ZS4 under the transmission electron microscopy (TEM). The lack of chlorophyll-protecting material or the chloroplast grana degradation causes the leaf fade.
\end{abstract}

\section{Keywords}

Biosynthesis and Degradation, TEM, Chlorophyll, Leaf Color Mutant, Tomato

\begin{abstract}
Abbreviations
Pn: Net photosynthetic rate; Gs: Stomatal conductance; Ci: Intercellular $\mathrm{CO} 2$ concentrations; Tr: Transpiration rate; Fv/ Fm: Maximum quantum efficiency of PSII; Y(II): Actual photosynthetic efficiency; qP: Photochemical quenching; qN: Nonphotochemical quenching; ETR: Absolute electron transfer rate; Chl: Chlorophyll; Ccar: Carotenoids; SOD: Superoxide dismutase; POD: Peroxidase
\end{abstract}

\section{Introduction}

Most plants are mainly green in nature. The chlorophyll content is one of the important determinants of leaf color. Leaf color variation usually affects photosynthetic efficiency and causes crop failure. In 1991, Parks proved the biliverdin IX [alpha] is an indispensable substance for the synthesis of pigment groups, which used the yellow mutant hy1 and hy 2 [1]. In recent years, people realized the value of leaf color mutation. Leaf color mutants have become a valuable material for studying photosynthesis.

Yellow mutantion have been reported in many crops such as rice, barley, pea, cotton, tobacco, and tomato (Solanum lycopersicum) $[2,3]$. Similarly, leaf color mutants have been found in various cereal crops [4-6] and most of these mutations are nuclear recessive traits. The mutant $y / c, y g 17, c h / 1$ and ch/9 are all controlled by single recessive nuclear genes [7-9]. The leaf color mutant of rice has been studied comprehensively. The leaf color phenotypic could be used as marker. Meanwhile, it also could be used to study photosynthesis $[10,11]$.
Chlorophyll (Chl) is one of the important photosynthetic pigments. The content of chlorophyll could directly affect the plant photosynthesis. The reduce of $\mathrm{Chl}$ (b) (chlorophyll b) content could directly lead the photosynthetic less $[12,13]$. Low levels of chlorophyll may lead to unhealthy plants. But some leaf color mutants could allow plants normal survive. Most of these mutants do not change all leaves to yellow. The green tissue could provide enough carbohydrates [14]. Leaf color fade is caused by inhibition of chlorophyll biosynthesis or rapid degradation. In previous study, most of the main reason of $\mathrm{Chl}$ reductions was a partial block in the $\mathrm{Chl}$ synthesis

*Corresponding author: He Zhang, College of Horticulture and Landscape Architecture, Northeast Agricultural University, Harbin, China

Accepted: October 27, 2020

Published online: October 29, 2020

Citation: Mo-zhen C, Hao-nan Q, Fu-lei M, et al. (2020) The Chlorophyll Biosynthesis and Degradation and Chloroplast Structure in Tomato Yellow Mutant. J Hortic Sci Res 3(1):113-124 
pathway $[13,15]$. Many leaf color mutants such as the mutant $C A O$ Oster, et al. [16] and $C H L H$ play an important role in the study of chlorophyll biosynthesis. A variety of factors can affect the biosynthesis of chlorophyll. The excess heme could control chlorophyll synthesis via negative feedback to form the leaf color mutant [17]. $\delta$-amino levulinic acid (ALA) also plays an important role in chlorophyll bio-synthesis. Martin Muller, et al. [18] provided exogenous ALA to the barley leaf color mutant in dark conditions, and the leaves still could change to green. Muller indicated the chlorophyll biosynthesis was not controlled by light [18]. The accumulation of protoporphyrin (Proto) and Mg-porphyrins were demonstrated playing the important role in Chl biosynthesis used the Chlorella mutants by Granick, et al. $[19,20]$. The silencing or inactivation of major genes role in chlorophyll bio-synthesis also could cause the plant leaves color faded green [21].

The only way of plants getting carbon is photosynthesis. Leaf color mutants are widely used to improve photorespiration efficiency and yield of crops. Coschigano, et al. [22] identified the GLUI gene from the Arabidopsis leaf color mutant gls and proved the GLUI was associated with photorespiration [22]. This discovery provides a new way to improve crop yield by inhibiting the photorespiration of $C_{3}$ crops to increase photosynthetic efficiency. In addition Gan and Amasino, et al. [23] identified a tobacco evergreen mutant which could obtain an apparent delay in aging, meanwhile the biomass and seed yield increased by $40 \%$ and $52 \%$ compared to wild-type tobacco [23]. The tomato mutant $n v$ was a common leaf color mutant. The study of leaf color mutants can improve the understanding of plant photosynthesis and the role of chlorophyll in the presence of plants.

Redox reactions play an important role in plant photosynthesis. The reactive oxygen species (ROS) come from photosynthesis and respiration in plants, and chloroplasts are the main organelles produced ROS [24]. If $\mathrm{C}_{3}$ plants grow under the high-light, drought and low-temperature conditions, ROS will accumulate with the photorespiration increasing [25]. ROS is considered unfavorable products in aerobic condition. Excess ROS production could cause the plant death. If more light was assimilated, the plant will cause the photo-oxidative [26]. Superfluous light energy is used to synthesize ROS or some toxic free radicals $[27,28]$. To avoid the occurrence of this phenomenon, plants utilize a range of self-protective mechanisms [28-32]. Carotenoids Adams, et al., Frank, et al. $[33,34]$ alpha-tocopherol, ascorbic acid (ASA) Nicholas, et al. [35] and glutathione (GSH) could keep the dynamic balancing process in plant photosynthesis. Keeping balancing requires the collective function of multiplication protective mechanisms. Here we also focus on the chlorophyll biosynthesis or degradation pathways which cause the leaf color change to yellow in tomato mutant $y m$.

Except the pigment content the balance of photosystem I (PSI) and photosystem II (PSII) is crucial in yellow leaf mutants [36]. The plant reduces to the imbalance in light absorption usually used to change distribution of PSI and PSII [37]. Non-photochemical quenching (NPQ) is the key process in PSII, by harmlessly dissipated excess light energy [38]. It is induced by a $\mathrm{pH}$ difference value in thylakoid lumen which is generated by photosynthetic electron transport under excess of light [39]. Meanwhile the PSI and PSII may linear electron transport under stress conditions too [40].

There are many contentious issues in the field of photoprotective responses, and still need further research. Many leaf color mutants were used in the study of plant photosynthesis. Here we used the transmission electron microscopy to obtain the structure of the mutant $y m$ and control zs4's chloroplast. The gas exchanges parameters and fluorescence parameters of $y m$ and $z s 4$ were measured. We measured the photosynthetic prerequisite, chlorophyll-degrading enzyme and the key enzyme of redox in plant. It is interesting to note most leaf color mutants have weak growth potential, but ym had similar growth vigor and biomass compared with the control zs4. The yellow mutant is used to simplify identification of hybrid purity and improve the efficiency of field purity identification in the hybrid production. The study of yellow mutant was necessary and valuable.

\section{Materials and Methods}

\section{Plant materials}

The genetically stable, yellow-leaves mutant tomato variety $y m$, the green-leaves tomato variety $z s 4$ were provided as gifts by the Tomato Research Institute of Northeast Agricultural University in China (Figure 1). All plants were raised in the greenhouse of Northeast Agricultural University $\left(25^{\circ} \mathrm{C}\right.$, $16 \mathrm{~h}$ light and $8 \mathrm{~h}$ dark), Harbin, China, in 2017-2019. The mutant $y m$ was a natural mutation from zs4. It was crossed with zs4 to produce $F_{1}, F_{2}$ progeny for agronomic trait analyses.

\section{The content of the plant photosynthetic pigment}

$0.1 \mathrm{~g}$ leaves of mutant $y m$ and control zs4 (After sowing 9, 12,15 and 60 days) were grind into a homogenate in $10 \mathrm{~mL}$ of $95 \%(\mathrm{v} / \mathrm{v})$ ethanol in dark until became white. Absorbances were measured at 663, 645, and $470 \mathrm{~nm}$. Chlorophyll a (Chla) and chlorophyll b (Chlb) content were measured by the spectrophotometric. The experiment followed three biological iterations. Triplicate of experiments were performed.

$$
\begin{aligned}
& C h l(a)=13.95 A_{663}-6.8 A_{645} \\
& C h l(b)=24.96 A_{645}-7.32 A_{663} \\
& C_{c}=18.16 A_{649}+6.63 A_{665}
\end{aligned}
$$

\section{Transmission electron microscopy (TEM) of the chloroplast}

The mutant $(y m)$ was changed yellow when it cotyledon period. Two time points were chose (5 leaves and 10 leaves) to observe by using the transmission electron microscopy. Cut the leaves of these 2 points $y m$ and zs 4 into $1 \mathrm{~mm} \times 2 \mathrm{~mm}$ segments, fixed with $2 \%(\mathrm{v}: \mathrm{v})$ glutaraldehyde, washed with $1 \%$ (w:v) PBS (0.1 M each $\mathrm{Na}_{2} \mathrm{HPO}_{4} \cdot 12 \mathrm{H}_{2} \mathrm{O}$ and $\mathrm{NaH}_{2} \mathrm{PO}_{4} \cdot 2 \mathrm{H}_{2} \mathrm{O}$ in saline), and fixed in $1 \%$ (w:v) osmic acid (pH 7.2) for $12 \mathrm{~h}$ at $4{ }^{\circ} \mathrm{C}$. The samples were then washed with $1 \%$ (w:v) PBS; sequentially dehydrated with $50 \%, 70 \%, 80 \%, 90 \%$, and $100 \%$ (v:v) acetone then join in epoxy resin. Sectioned and viewed under the H-7700 canning TEM (Hitachi Ltd., Tokyo, Japan). 

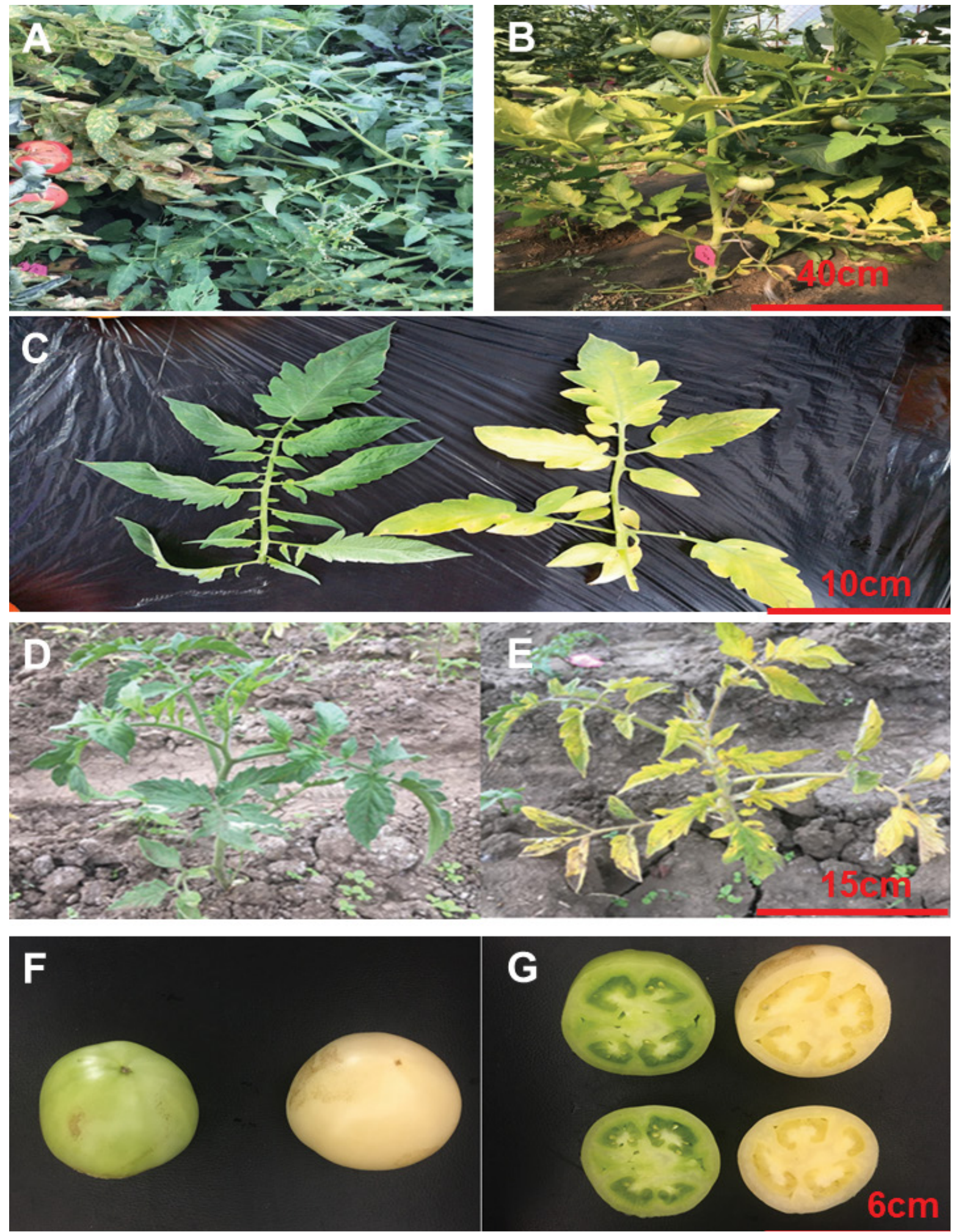

Figure 1: The green leaf tomato zs4 and the yellow leaf tomato mutant $y m$. A) The $z s 4$ in mature stage; B) The $y m$ in the mature stage; C) The leaf of $z s 4 ; D)$ The leaf of $y m$; E) The $y m$ in the seeding stage; F) The $z s 4$ in the seeding stage; G) The compare of $z s 4$ (Green) and ym (yellow) fruits.

\section{Gas exchange measurements}

Portable photosynthetic rate tester (Li-6400) was used in here. The growth well fruiting period tomatoes $y m$ and it control zs4 were choice. We measure the gas exchange at 5 time points. Repeat three times at each group. The method of using the Li-6400 was reference [41].

\section{Chlorophyll fluorescence measurements}

The growth well fruiting period tomatoes $y m$ and it control zs4 were choice for measurement. Pulse fluorometer FMS2 
(Hansatech, The British) was used on fluorescence parameter determination of $y m$ and $z s 4$. Dark stress the leaves $30 \mathrm{~min}$ then open the detect light $\left(<0.05 \mu \mathrm{mol} \mathrm{m} \mathrm{m}^{-2} \mathrm{~s}^{-1}\right)$ to get $\mathrm{F}_{0}$. Open the saturated pulse light $\left(12000 \mu \mathrm{mol} \mathrm{m}^{-2} \mathrm{~s}^{-1}\right)$ to measure the $\mathrm{F}_{\mathrm{m}}$. Repeat three times at each group. These two results were used to calculate the fluorescence parameter determination:

PSII photochemical relative quantum efficiency (DPSII) $=$ $\left(F_{m}{ }^{\prime}-F_{s}\right) / F_{m}{ }^{\prime}$

Photochemical quenching $(\mathrm{qP})=\left(\mathrm{F}_{\mathrm{m}}{ }^{\prime}-\mathrm{F}_{\mathrm{s}}\right) /\left(\mathrm{F}_{\mathrm{m}}{ }^{\prime}-\mathrm{F}_{0}{ }^{\prime}\right)$

Non photochemical quenching $(N P Q)=\left(F_{m}-F_{m}{ }^{\prime}\right) / F_{m}{ }^{\prime}$

Maximum photochemical efficiency of PSII under dark adaptation $\left(F_{v} / F_{m}\right)=\left(F_{m}-F_{0}\right) / F_{m}$

\section{Measurement of the levels of chlorophyll pre- cursor substances}

The growth well fruiting period tomatoes $y m$ and it control zs 4 were choice for measurement. $1 \mathrm{~g}$ of the dark-treated leaves induced with $20 \mathrm{mmol} \cdot \mathrm{L}^{-1}$ acetyl propionate and $4 \%$ trichloroacetic acid (w:v) was extracted, and a cationic exchange resin with a $\mathrm{pH}$ value of 4.2 was obtained. Ehrlich-Hg reagent was added, and ALA content was measured at $553 \mathrm{~nm}$. PBS was used to extract the PBG, and then, the chromogenic Ehrlich-Hg reagent was added, and the OD value was measured at $553 \mathrm{~nm}$. Triplicate of experiments were performed.

$1 \mathrm{~g}$ of tomato leaves was weighed out, ground in liquid nitrogen, and centrifuged at $18,000 \times \mathrm{g}$ for $10 \mathrm{~min}$. $\mathrm{Na}_{2} \mathrm{~S}_{2} \mathrm{O}_{3}$ was added, and the sample was vigorously agitated and exposed to strong light for $20 \mathrm{~min}$. The $\mathrm{pH}$ was adjusted to 3.5 using $1 \mathrm{M}$ formic acid. The sample was extracted three times in diethyl ether, and the OD values of the aqueous phases were measured at $405.5 \mathrm{~nm}$. Three milliliters of $0.1 \mathrm{M} \mathrm{HCL}$ were used to leach the copro from the ether extract, and then, $3 \mathrm{ml}$ of $1.37 \mathrm{M} \mathrm{HCL}$ was used to leach the proto. The copro and proto were combined, and then, 1.37M HCL was used to adjust the volume to $10 \mathrm{~mL}$, and the $\mathrm{OD}$ was measured at $408 \mathrm{~nm}$. Triplicate of experiments were performed. $10 \mathrm{~mL}$ acetone (extracted by $\mathrm{N}$-hexane) was used to extract $1 \mathrm{~g}$ of dark-treated yellow leaves.

The fluorescence integral of Mg-Proto:

$$
\text { Mg-Proto }=(1.11) E_{420} \int_{592}{ }^{620} f_{(\lambda)} d_{\lambda}-(0.91) E_{420} \int_{570}^{592} f_{(\lambda)} d_{\lambda}
$$

$2 \mathrm{~g}$ of dark-treated yellow leaves were selected, ground in an ice bath, and dissolved in $20 \mathrm{~mL}$ of liquor ( $\mathrm{V}$ acetone: $\mathrm{V}_{\mathrm{NH} 3}$. ${ }_{\mathrm{H} 2 \mathrm{O}}=9: 1$ ). Then, $20 \mathrm{~mL}$ of the acetone solution was extracted with $\mathrm{N}$-hexane. Triplicate of experiments were performed.

The emission fluorescence intensity of the acetone phase (substrate):

$$
\text { Pchlide }=\left(E_{440} F_{640}-0.03 E_{400} F_{633}\right) / 0.99
$$

\section{Study of the enzyme involved in chlorophyll deg- radation}

The growth well fruiting period tomatoes ym and it control $z s 4$ were choice for measurement. Fresh yellow leaves of the $y m$, and normal leaves of the $z s 4$ were selected. $5 \mathrm{~g}$ of the leaves were weighed out [42]. Then, $4 \mathrm{ml} \cdot \mathrm{g}^{-1} \mathrm{FW}$ standard extract I was added (50 mM Tris- $\mathrm{HCl}(\mathrm{pH} 8)$ and $0.4 \mathrm{M}$ sucrose). The mixture was ground in an ice bath and filtered through a nylon cloth. Then, the filtrate was centrifuged at $12000 \times \mathrm{g}$ for $10 \mathrm{~min}$ at $4{ }^{\circ} \mathrm{C}$, and $5 \mathrm{ml}$ of $50 \mathrm{mM}$ Tris- $\mathrm{HCl}(\mathrm{pH} 8)$ was added. The suspended sediment was then centrifuged again and resuspended in acetone $\left(-20^{\circ} \mathrm{C}\right)$. The sediment was dried to obtain the acetone powder, which was stored at $-20^{\circ} \mathrm{C}$ until further application. Thirty milligrams of the acetone powder were weighed out, and $0.167 \mathrm{ml} \cdot \mathrm{mg}^{-1}$ standard extract II was added (50 mM PBS ( $\mathrm{pH} 7.5$ ), $50 \mathrm{mM} \mathrm{KCl}$ and $0.24 \%$ Triton- $X$ 100). The mixture was ground in ice; the grinding fluid was incubated for $1 \mathrm{~h}$ at $30^{\circ} \mathrm{C}$ and then centrifuged at $12,000 \times \mathrm{g}$ for $10 \mathrm{~min}$ at $4{ }^{\circ} \mathrm{C}$, and the supernatant was extracted (Minguez-Mosquera). Petroleum ether was used to extract $\mathrm{Chl}$ from fresh green spinach, and the substrate concentration was calculated (Fernandez-Lopez). Then, $0.5 \mathrm{ml}$ of $50 \mathrm{mM}$ PBS $(\mathrm{pH} 7.5), 1 \mathrm{~mL}$ of chlase and $2 \mathrm{~mL}$ of a $\mathrm{Chl}$ solution in acetone (0.2 $\mathrm{mM} \mathrm{Chl}$ ) were mixed in a water bath at $45^{\circ} \mathrm{C}$ for $30 \mathrm{~min}$. Then, $0.5 \mathrm{~mL}$ of the reagent and $4.5 \mathrm{~mL}$ of extracting solution III (Vacetone : Vpetroleum ether $=1: 2$ ) were mixed with sufficient agitation and centrifuged at $8,000 \times \mathrm{g}$ for $6 \mathrm{~min}$ at $4{ }^{\circ} \mathrm{C}$ until separation. The $\mathrm{OD}$ of the bottom phase obtained was measured at $665 \mathrm{~nm}, 667 \mathrm{~nm}$ and $651 \mathrm{~nm}$, and the extinction coefficients of $54.1 \mathrm{Chl}, 74.9 \mathrm{Chl}$ (a) and $47.0 \mathrm{mM} \mathrm{cm}^{-1} \mathrm{Chl}$ (b) were used to obtain the reacting weights. Triplicate of experiments were performed.

\section{The key enzyme activity of redox}

The growth well fruiting period tomatoes ym and it control zs 4 were choice for measurement. Superoxide dismutase (SOD), peroxidase (POD), and catalase (CAT) activities were measured by the nitro blue tetrazolium (NBT) photoreduction method Ries, et al. [43], guaiacol method Anderson, et al. [44] and ultraviolet absorption method Cakmak, et al. [45] respectively.

$5 \mathrm{~mL}$ of $50 \mathrm{mM}$ Tris- $\mathrm{HCl}$ buffer (containing $1 \mathrm{~mL}$ glycerin, $1 \mathrm{mM}$ ASA, $1 \mathrm{mM}$ DTT, $1 \mathrm{mM}$ EDTA, $1 \mathrm{mM}$ GSH and $5 \mathrm{mM}$ $\mathrm{MgCl}_{2}$ ) was added, and the sample was ground in a mortar in ice and then centrifuged at $20,000 \times \mathrm{g}$ at $4{ }^{\circ} \mathrm{C}$ for $30 \mathrm{~min}$. The reaction fluid included $50 \mathrm{mM}$ Tris- $\mathrm{HCl}(\mathrm{pH} 7.5)$ buffer solution, $5 \mathrm{mM} \mathrm{MgCl}, 0.5 \mathrm{mM}$ GSSG and $0.2 \mathrm{mM} \mathrm{NADPH}$, and the final volume was $1.2 \mathrm{~mL}$ GSSG was added to start the reaction. Triplicate of experiments were performed.

To measure ascorbate peroxidase (APX) activity, $1 \mathrm{~g}$ of leaves (no vein) was selected and ground in a mortar with 3 $\mathrm{mL}$ of $50 \mathrm{mM}$ PBS (containing EDTA- $\mathrm{Na}_{2}$ ). The homogenate was filtered through a double gauze and then centrifuged at $10,000 \times$ g centrifuged for $10 \mathrm{~min}$. Thee milliliters of reaction liquid (including $50 \mathrm{mM}$ PBS (pH 7.8), $0.1 \mathrm{mM}$ EDTA, $0.1 \mathrm{mM}$ $\mathrm{H}_{2} \mathrm{O}_{2}$ and $0.5 \mathrm{mM} \mathrm{ASA}$ ) was added and mixed, and crude enzyme activity was measured by monitoring the variation in OD value at $290 \mathrm{~nm}$ for 30s (Mishra). Triplicate of experiments were performed.

\section{Chlorophyll protection}

Pigment extraction was performed as described in section 2.1.3 for chlorophyll. The OD value was measured at 470 
$\mathrm{nm}$, and the carotenoid concentration $\left(\mathrm{mg} \mathrm{L}^{-1}\right)$ was calculated as follows. The determination of protein content was based on the Bradford method, with bovine serum albumin as a standard.

$$
C_{c a r}=\left(1000 A_{470}-2.05 \mathrm{Chl}(\mathrm{a})-114.8 \mathrm{Chl}(\mathrm{b})\right) / 248
$$

\section{Results}

\section{Investigation of genetic law in ym mutant}

Tomato yellow mutant $y m$ and $z s 4$ were respectively used for female parent $\left(P_{1}\right)$ and male parent $\left(P_{2}\right)$. Cross pollination in a greenhouse. All $F_{1}$ progeny had green leaves. $F_{2}$ plants showed 193 green leaves and 59 yellow leaves, respectively (total 252). The result was same with the predicted 3:1 segregation $(p<0.05)$. The result showed that a single recessive nuclear gene regulates the yellow leaves mutation in $y m$.

\section{The ym mutant showed multifarious fade pheno- type}

The leaves of yellow mutant ym appears to fade to green. But the growth trend was similar to the control line of zs4. Meanwhile the fruit also exhibited a loss of greenness (Figure $1)$.

\section{Pigment content in different developmental pe- riods}

Chlorophyll and carotenoid contents were measured at 9, 12, 15 and 60 days (Table S1), (Figure 2A). After 15 days, the
Chl content in mutant ym decreased sharply to only $39 \%$ of that in zs4 (CK). Sixty days later, in the leaves of the mutant $y m$, the total chlorophyll content was $36 \%$ that in the leaves of the control zs4. Total chlorophyll content of the mutant $y m$ was always less than that of the zs4. After 15 days, the $\mathrm{Chl}$ (a)/ $\mathrm{Chl}$ (b) levels were relatively higher than the initial values. At 60 days, the $\mathrm{Chl}(\mathrm{a}) / \mathrm{Chl}(\mathrm{b})$ levels in the leaves of both the mutant $y m$ and $z s 4$ were twice lower than it in 9 days (Figure 2B).

\section{Observation of chloroplast ultrastructure}

The result suggested that the chloroplasts of the green cotyledons were normal (zs4) (Figure $3 \mathrm{~A}$ and Figure $3 \mathrm{C}$ ), but the chloroplasts of the mutant yellow cotyledons were very unevenly distributed in the cell (Figure 3B), and most chloroplast membranes had started to be degraded $(y m)$ (Figure 3D). Observation of the green areas of the second leaves of $y m$ and $z s 4$ revealed that the mutant ym hardly retained the double membrane structure, and only some of the chloroplasts perfectly retained their lamellar structures (Figure 3F). However, the chloroplasts of the control zs4 had complete double membrane structures (Figure $3 \mathrm{E}$ and Figure $3 \mathrm{G}$ ). The yellow leaves of the $y m$ mutant exhibited completely degraded chloroplasts (Figure $3 \mathrm{H}$ ).

\section{Measurement of the photosynthetic parameters of the yellow mutant}

The $P_{n}$ (net photosynthetic rate) and $G_{s}$ (stomatal conductance) trends were similar, and the $P_{n}$ values for both the mutant $y m$ and the control zs4 decreased markedly at high light
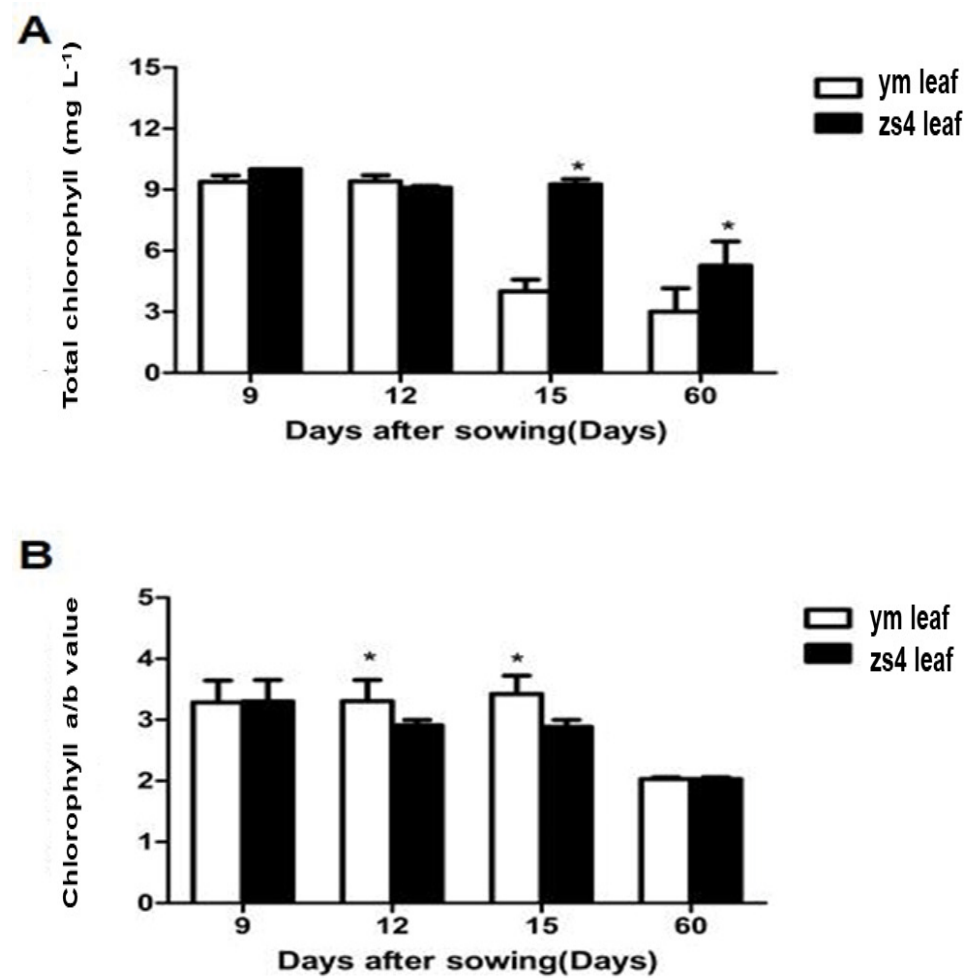

Figure 2: A) Changes in total chlorophyll content; B) Changes in the chlorophyll a/b value.

Note: Error bars represent the standard deviation for three independent replicates. Significant differences were analysed by ANOVA, and the asterisk indicates significant differences in comparison with the $z s 4$ at $P<0.05$. Triplicate of experiments were performed. 

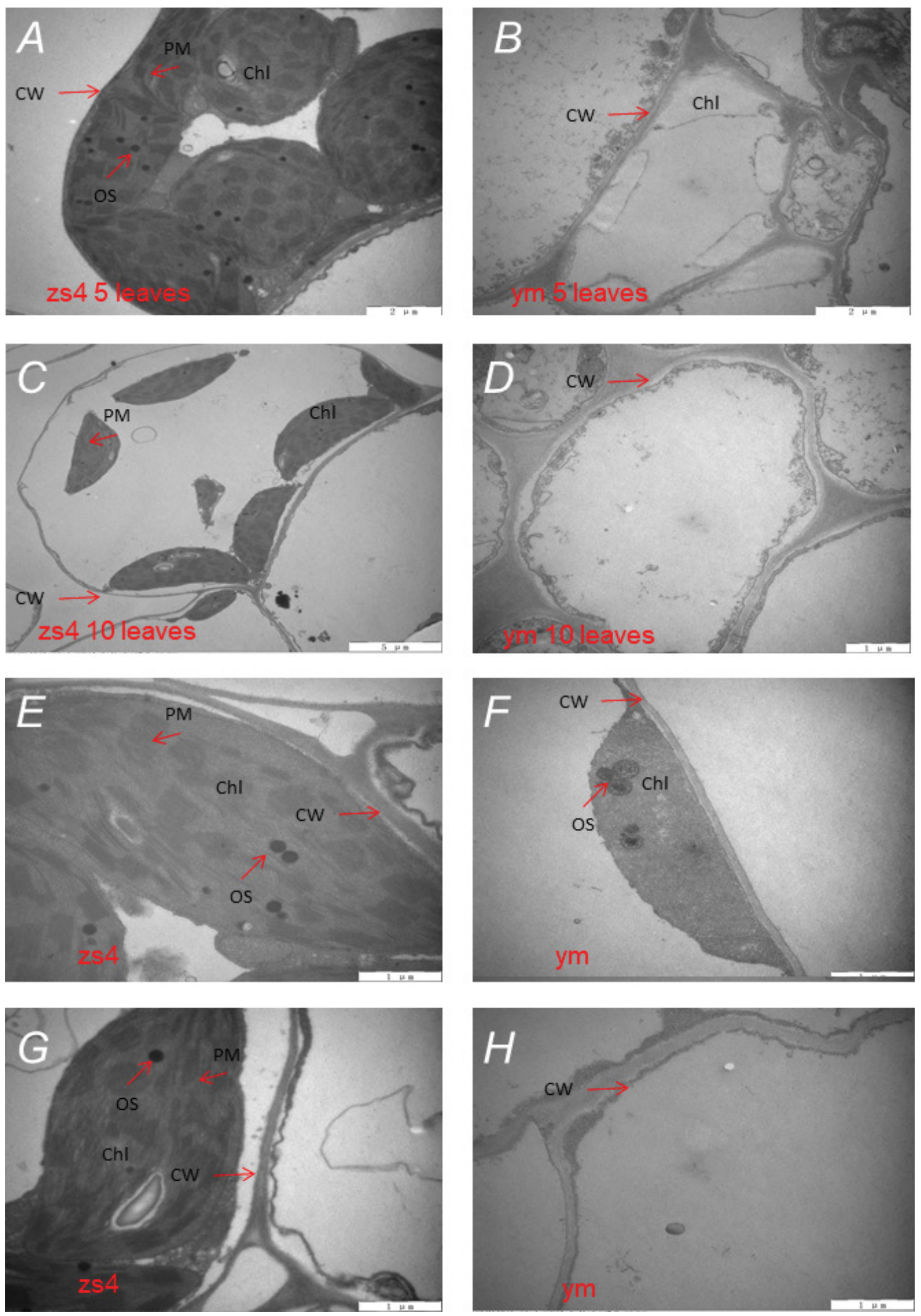

Figure 3: Observation of chloroplast ultrastructure of the $y m$ and $z s 4$ under TEM. A\&C) The zs4 green leaves' whole cell chloroplast distribution; B\&D) The ymmutant leaves' whole cell chloroplast distribution; E\&G) The zs4 green leaves' chloroplast lamellar structure observation; $\mathrm{F} \& \mathrm{H}$ ) The chloroplast lamellar structure observation of ym mutant leaves.

Note: CW: Cell wall; PM: plasma membrane; Chl: chloroplast; OS: Osmiophilic granule. 


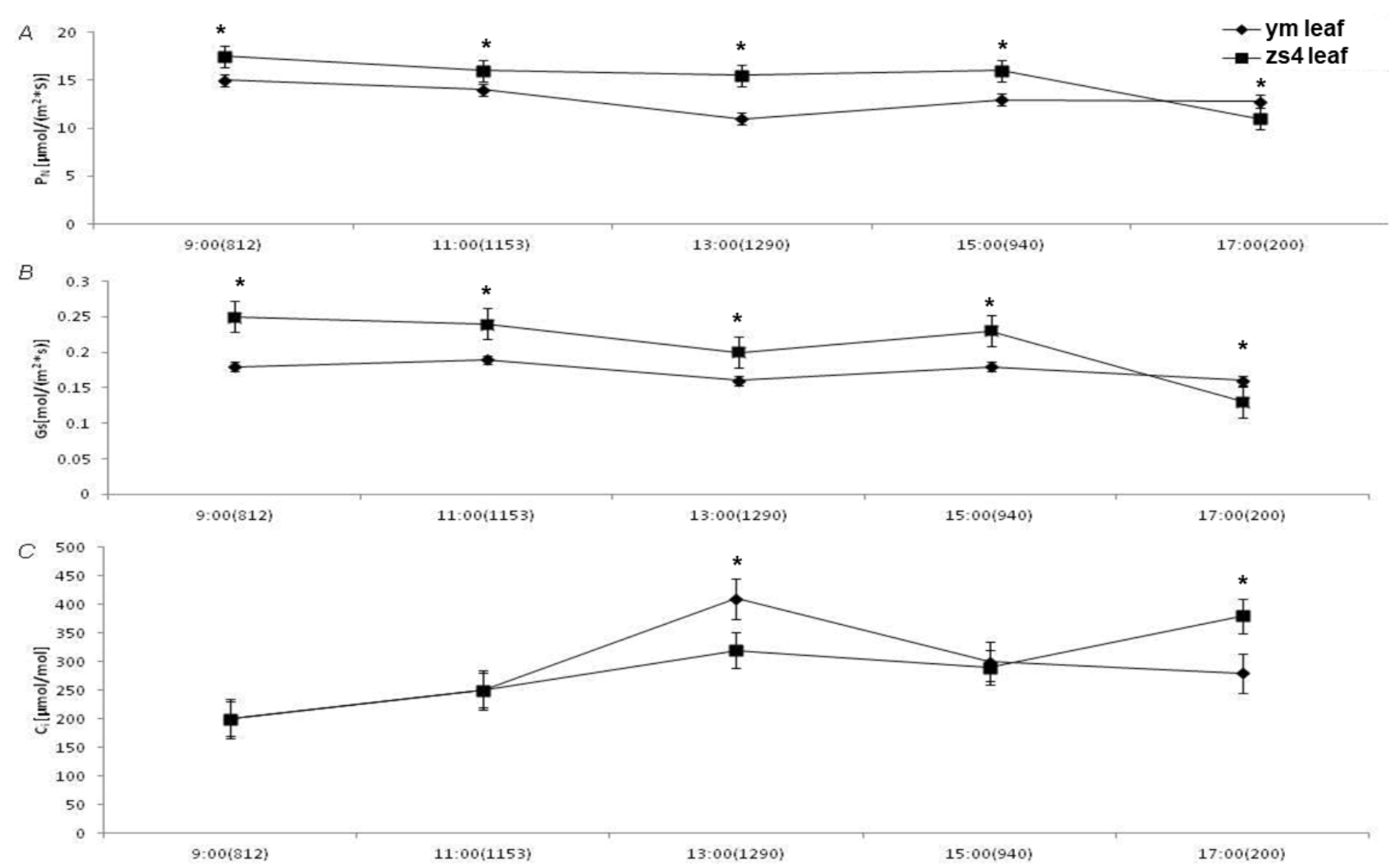

Figure 4: Gas-exchange parameter of the leaves of the mutant $y m$ at different light intensities. A) netphotosyntheticrate; B) Stomatalconductance; C) Intercellular carbon dioxide concentration.

Note: Significant differences were analysed by ANOVA, and the asterisk indicates significant differences in comparison with the zs4 at $P<0.05$. Triplicate of experiments were performed.

intensity. However, the $P_{n}$ of $y m$ decreased faster than that of zs4. $G_{s}$ showed a similar trend. The $P_{n}$ of $y m$ was higher than that of the control zs4 when the light intensity was under 200 $\mu \mathrm{mol} \cdot \mathrm{m}^{-2} \cdot \mathrm{s}^{-1}$. Throughout the process, the trend observed for $\mathrm{C}_{\mathrm{i}}$ (internal carbon dioxide concentration) was the opposite of that observed for $P_{n}$ (Figure 4).

The PSII maximum photochemical quantum yield $\left(F_{v} / F_{m}\right)$ and effective photochemical quantum yield $\left(F_{v}{ }^{\prime} / F_{m}{ }^{\prime}\right)$ were constant. Notably, the effective photochemical quantum yield of $y m$ was slightly lower than that of $z s 4$ at high light intensity, but at low light intensity, the trend was reversed. The PSII actual photochemical quantum yield (DPSII) had the same variation trend as $F_{v}{ }_{v} / F_{m}{ }^{\prime}$. Photochemical quenching $\left(q_{p}\right)$ of the mutant $y m$ and the control zs4 showed a tendency to occur at higher light intensity. The photochemical quenching of $y m$ was slightly lower than that of $z s 4$ at $200 \mu \mathrm{mol} \cdot \mathrm{m}^{-2} \cdot \mathrm{s}^{-1}$ light intensity. The non-photochemical quenching (NPQ) of mutant $y m$ changed steadily, while that of the control zs4 showed a tendency to decrease with increasing light intensity. The apparent electron transfer rate (ETR) of zs4 was significantly higher than that of $y m$ except at a light intensity of $940 \mu \mathrm{mol} \mathrm{m} \mathrm{m}^{-2} \mathrm{~s}^{-1}$ (Figure 5).

\section{Analysis of chlorophyll synthesis pathway}

The chlorophyll content of the mutant ym was lower than $z s 4$. The chlorophyll $b$ content of ym decreased more than that of $z s 4$. The carotenoid content of $y m$ was also signifi- cantly lower than that of zs4 (Table S2). The chlorophyll precursors of $y m$ and $z s 4$ revealed that there was no precursor accumulation or absence throughout the process (Figure 6).

\section{The chlorophyll degradation pathway}

The activity of the chlorophyll-degrading enzyme in the $y m$ was higher than that in the control variety zs4 (Figure 7). More chlase could accelerate the decomposition of chlorophyll, which may cause the leaf lose green in the mutant ym.

\section{The key enzyme activity of redox}

Two time points ( 5 and 10 leaves) were used to measure SOD, POD, CAT, glutathione reductase (GR) and APX activities. The results showed the APX content in ym variety was always higher than in zs4 (Figure 8). The chlorophyll/carotenoid contents of the $y m$ and $z s 4$ decreased during the cotyledon period. The level of the $y m$ was higher than zs4 at 12 days. But at 15 days, the values for the $y m$ were lower than zs4 (Table 1 ).

\section{Discussion}

Photosynthetic efficiency has been identified as one of the key reason to improve the yield potential of the crops [46].

In this study, yellow leaf color mutant ym was obtained. After cross-fertilization, the whole first filial generation exhibited green leaves. While the leaf color segregation ratio of the second filial generation was 3:1 (green:yellow), which 

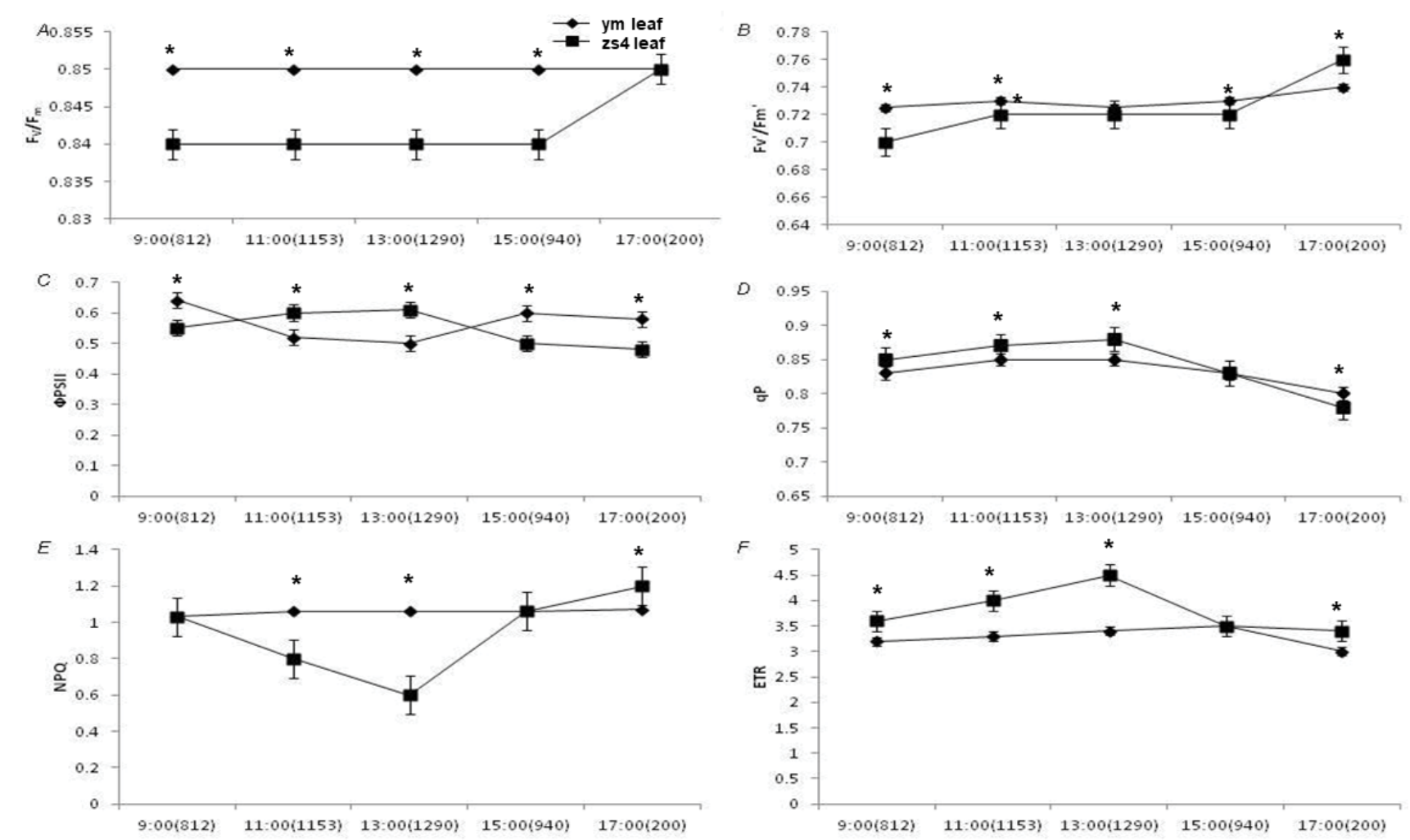

Figure 5: Chlorophyll fluorescence parameters of the leaves at different light intensities. A) Maximum quantum yield of PSII photochemistry; B) $\mathrm{F}_{v} / \mathrm{F}_{\mathrm{m}}$; C) Quantum efficiency of PSII; D) Photochemical quenching coefficient; E) Non-photochemical quenching; $F$ ) Apparent rate of electron transport at the PSII level.

Note: Significant differences were analysed by ANOVA, and the asterisk indicates significant differences in comparison with the zs4 at $P<0.05$. Triplicate of experiments were performed.

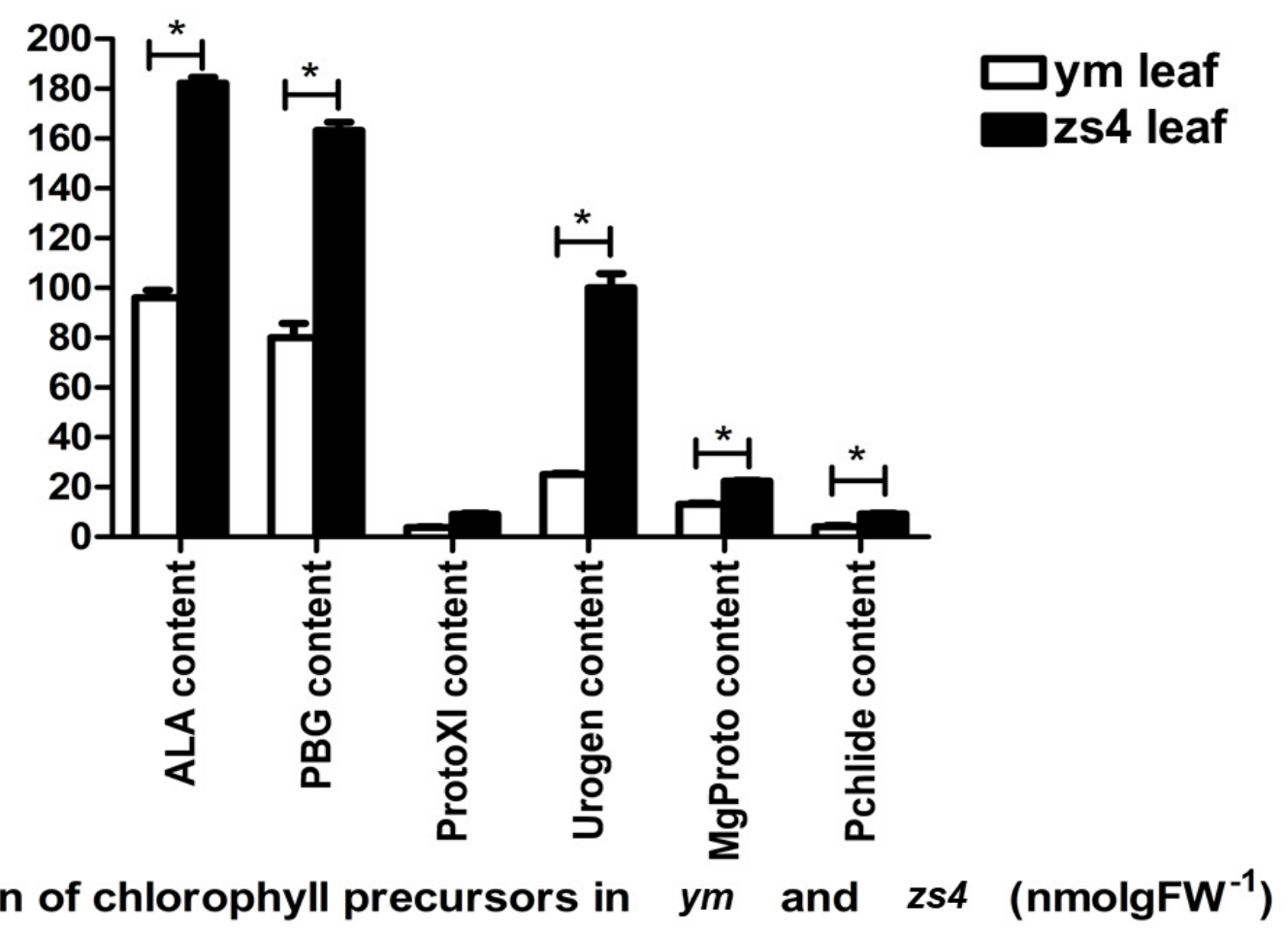

Figure 6.The comparison of chlorophyll precursors in ym and zs4. Triplicate of experiments were performed. 


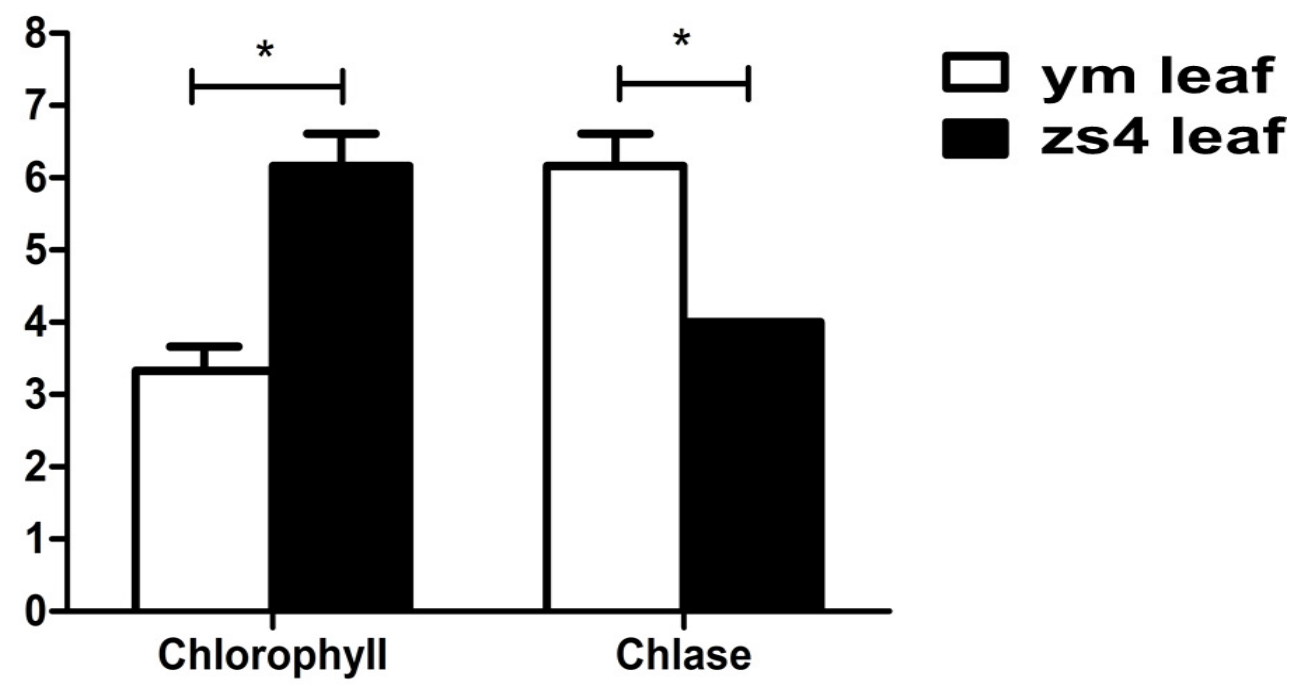

Figure 7: Chlorophyll content and chlorophyllase activity of $y m$ and zs4. Triplicate of experiments were performed.

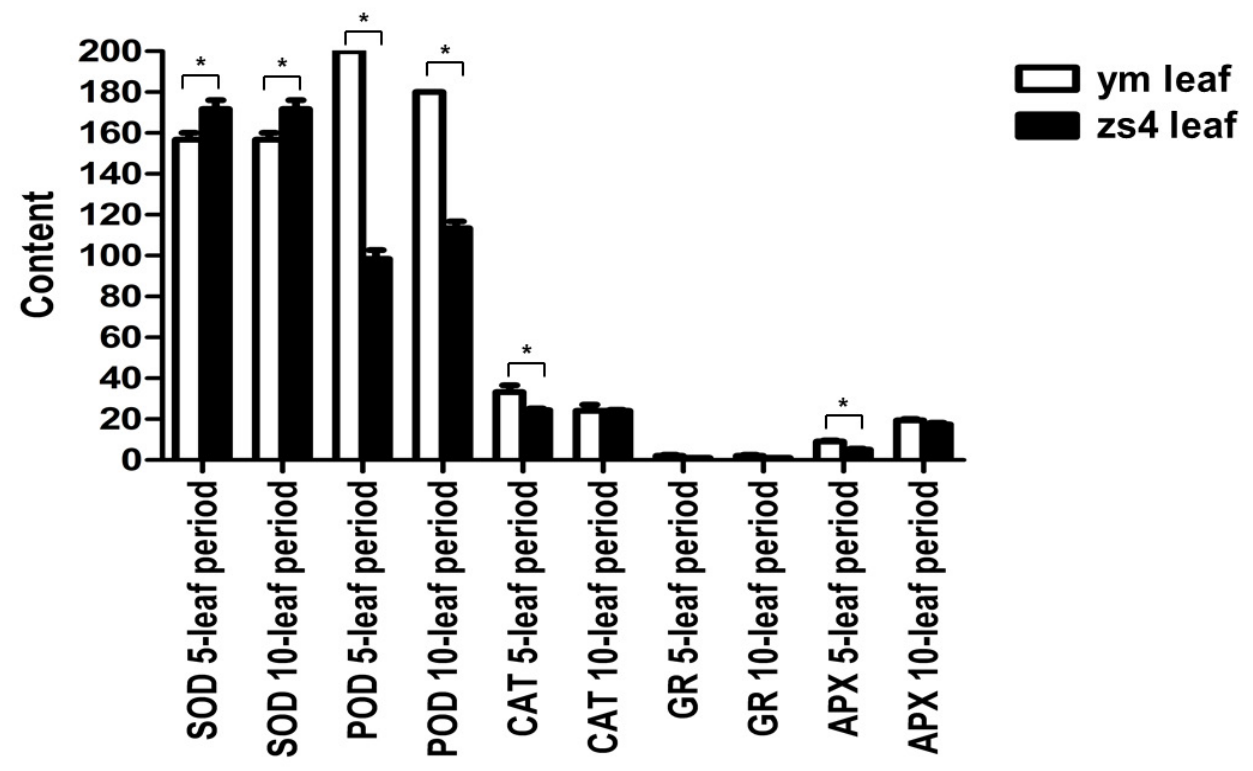

Figure 8: Comparison of the key enzyme activity of redox in $y m$ and zs4. Significant differences were analysed by ANOVA, and the asterisk indicates significant differences in comparison with the $z s 4$ at $\mathrm{P}<0.05$. Triplicate of experiments were performed.

Table 1: Carotenoid content and ratio total chlorophyll to carotenoid content.

\begin{tabular}{|l|l|l|l|l|}
\hline \multicolumn{1}{|c|}{ Time point } & \multicolumn{1}{c|}{ 9d } & \multicolumn{1}{c|}{ 12d } & \multicolumn{1}{c|}{ 15d } & \multicolumn{1}{c|}{ 60d } \\
\hline$Y m C_{c}$ & $1.227 \pm 0.05^{\mathrm{b}}$ & $1.214 \pm 0.00^{\mathrm{b}}$ & $1.334 \pm 0.09^{\mathrm{b}}$ & $0.862 \pm 0.01^{\mathrm{b}}$ \\
\hline$y m C_{\mathrm{car}} / C_{c}$ & $7.012 \pm 0.06^{\mathrm{a}}$ & $7.453 \pm 0.02^{\mathrm{a}}$ & $2.786 \pm 0.06^{\mathrm{b}}$ & $2.412 \pm 0.09^{\mathrm{a}}$ \\
\hline$z s 4 C_{c}$ & $1.452 \pm 0.12^{\mathrm{a}}$ & $1.324 \pm 0.03^{\mathrm{a}}$ & $2.598 \pm 0.35^{\mathrm{a}}$ & $2.512 \pm 0.19^{\mathrm{a}}$ \\
\hline$z s 4 C_{c a r} / C_{c}$ & $6.769 \pm 0.26^{\mathrm{b}}$ & $6.36 \pm 0.43^{\mathrm{b}}$ & $3.634 \pm 0.15^{\mathrm{a}}$ & $2.247 \pm 0.42^{\mathrm{a}}$ \\
\hline
\end{tabular}

Data are presented as means $(n=3)$. Different lowercase letters $(a, b, c)$ indicate statistically significant differences $(P<0.05)$ between treatments in the same phenotype using LSD tests.

Note: $\mathrm{C}_{\text {car }}$ : Carotenoids, $\mathrm{C}_{\mathrm{c}}$ : Total chlorophyll content.

was consistent with Mendel's law [47]. The result explained that this phenotype was regulated by a single recessive nuclear gene. 15 days after seeding the $y m$ exhibited yellow. The chlorophyll deficiency caused the plant leaf change yellow.
The maintained chlorophyll a-to-b ratio could affect the photosynthesis [48]. The low $\mathrm{Chl}$ (b) content is associated also with the pleiotropic effects on photosynthesis [49]. In previous studies, the lack of chlorophyll content may improve the 
light distribution and light use efficiency in crops [50,51]. Here the ym total chlorophyll always lower than zs4, but the plant growth was not affected. The result in (Figure 2) and (Figure 4) shown the total Chl content in ym was gradually significantly lower than zs4. And with that the net photosynthetic rate of zs4 was higher than that of mutant ym at high light intensity. But when light intensity was low, the net photosynthetic rate of mutant ym was higher than that of ZS4. We suggest that the reason is the $\mathrm{Chl}$ content decrease may lead to significantly higher photosynthesis under the weak light [52].

Chloroplast protein mutations can cause defects in the structures of the inner membranes of chloroplasts [53]. We found that $y^{\prime}$ 's chloroplasts were detached from cell membranes under TEM. However, the zs4 chloroplasts were stable in cells. Meanwhile the TEM showed that the mutant ym chloroplasts' double-layer membrane structure was absent, and the basal laminar structure began to degrade. The results showed that the chloroplast lamellar structure was indeed damaged and the chloroplast membrane structure was damaged in the mutant lines $y m$. Thylakoid plays an important role in photosynthesis [54,55]. Chlorophyll is widely found in thylakoid membranes. Thylakoid membranes damage could lead to the $\mathrm{Chl}$ free and out of action even rapid degradation. The chloroplasts loss was the main reason of the leaves change yellow. Chlorophyll is rapidly broken down due to the breakdown of chloroplasts. Finally, the yellow traits are formed. Chlorophyll biosynthesis and degradation pathways were mean effects. Only one biosynthesis pathway was involved $[56,57]$. Carotene is the major substances protecting chlorophyll from damage [58]. In this study, ym carotenoids content in the total pigment was significantly lower than these in zs4. We suggest that the lack of the protect substances cause the chlorophyll unstable, which leads to the high levels of chloroplast cystic membrane and chlorophyll degradation. Ten days after seeding, the chlorophyll content began to decrease meanwhile it was accompanied by chloroplast degradation.

Light is the most important factor in the change of $y m$ mutant leaf color change. The photosynthetic coefficient and chlorophyll fluorescence parameters showed that under high light intensity $\left(1290 \mu \mathrm{mol} \cdot \mathrm{m}^{-2} \cdot \mathrm{s}^{-1}\right)$, the $P_{n}$ of $y m$ is significantly higher than zs4. The stomatal conductance $\left(G_{s}\right)$ also decreased severely. However, under low light intensity $(200 \mu \mathrm{mol} \cdot \mathrm{m}$ $\left.{ }^{2} \cdot \mathrm{s}^{-1}\right)$, the $\mathrm{P}_{\mathrm{n}}$ of $y m$ was lower than that of the $z s 4$. The trend of intercellular $\mathrm{CO}_{2}$ concentration $\left(C_{i}\right)$ is basically opposite to that of net photosynthetic rate. The balance in light absorption between PSI and PSII may decrease photosynthetic election flow. It could affect plant in some specific environmental conditions $[59,60]$. Under high light intensity, the effective photochemical quantum yield of ym PSII is slightly lower than zs4. At low light intensity, the effective photochemical quantum yield of $y m$ PSII was significantly higher than zs4. Here shown that mutant ym was more inhibited under high light intensity, while more resistant in low light intensity. It may be a better low light tolerance tomato germplasm.

The chlorophyll precursor substance of the mutant ym was significantly lower than that of the control plant zs4. Meanwhile, the chlorophyll enzyme content in the mutant leaf was significantly higher than that in the control plant $z s 4$. The results of REDOX activity showed that the REDOX ability of mutant $y m$ leaves was lower than that of control $z s 4$, and the $y m$ plants were more prone to senescence and death compared with zs4. We suggest that the possible reason for this phenomenon is the decrease of chlorophyll content due to the reduction of chlorophyll synthesis and protective substances in the plants, which affects the REDOX ability of the plants and produces the phenomenon of yellow leaf.

The lack of chlorophyll-protecting substance and chloroplast cystic membrane degradation were the main aspects caused the yellow leaf phenotype in the mutant $y m$. The leaves change yellow at the cotyledon flattening stage. And it grows vigorously. The mutant variety $y m$, which lacks chlorophyll in the seedling stage, could provide a platform for the study of chlorophyll. The mutant can be used as a seedling marker trait.

\section{Acknowledgments}

This research was supported by Natural Science Foundation of China (31501777); Harbin Applied Technology Research and Development Project (2017RAQXJ005).

\section{Author Contribution}

$\mathrm{MZC}$ and $\mathrm{HZ}$ conceived the experiments, $\mathrm{XNZ}$ and $\mathrm{XYW}$ conducted the experiments, JGY, LZ, FLM, HNQ analysed the results, MZC wrote the manuscript. All authors reviewed the manuscript.

\section{Conflicts of Interest}

The authors declare no conflict of interest.

\section{References}

1. Parks BM, Quail PH (1991) Phytochrome-deficient hy1 and hy2 long hypocotyl mutants of arabidopsis are defective in phytochrome chromophore biosynthesis. Plant Cell 3: 1177-1186.

2. Zhao J, Fang $Y$, Kang S, et al. (2014) Identification and characterization of a new allele for zebra leaf 2 , a gene encoding carotenoid isomerase in rice. South African Journal of Botany 95: 102-111.

3. Yan T, JR Zhu, Dianping Di, et al. (2015) Characterization of the complete genome of barley yellow striate mosaic virus reveals a nested gene encoding a small hydrophobic protein. Virology 478: $112-122$

4. Sawers RJH, Viney J, Farmer PR, et al. (2006) The maize oil yellow1 (oy1) gene encodes the i subunit of magnesium chelatase. Plant Mol Biol 60: 95-106.

5. Qin D, J Dong, F Xu, et al. (2015) Characterization and fine mapping of a novel barley stage green-revertible albino gene (hvsgra) by bulked segregant analysis based on ssr assay and specific length amplified fragment sequencing. Bmc Genomics 16: 838.

6. Li Zhaowei, Da Su, Bingting Lei, et al. (2015) Transcriptional profile of genes involved in ascorbate glutathione cycle in senescing leaves for an early senescence leaf (esl) rice mutant. J Plant Physiol 176: 1-15.

7. Ki-Hong J, Jung-he H, Choong-Hwan R, et al. (2003) Characterization of a rice chlorophyll-deficient mutant using the t-dna genetrap system. Plant Cell Physiol 44: 463-472. 
Citation: Mo-zhen C, Hao-nan Q, Fu-lei M, et al. (2020) The Chlorophyll Biosynthesis and Degradation and Chloroplast Structure in Tomato Yellow Mutant. J Hortic Sci Res 3(1):113-124

8. Deng XJ, Zhang HQ, Wang Y, et al. (2014) Mapped clone and functional analysis of leaf-color gene ygl7 in a rice hybrid (oryza sativa I. ssp. indica). PLoS One 9: e99564.

9. Li Q, Zhu FY, Gao X, et al. (2014) Young leaf chlorosis 2encodes the stroma-localized heme oxygenase 2 which is required for normal tetrapyrrole biosynthesis in rice. Planta 240: 701-712.

10. Li W, Tang S, Zhang S, et al. (2015) Gene mapping and functional analysis of the novel leaf color gene siygl 1 in foxtail millet [setariaitalica (I.) p. beauv]. Physiol Plant 157: 24-37.

11. Luan M, Xu M, Lu Y, et al. (2015) Expression of zma-mir169 mirnas and their target zmnf-ya genes in response to abiotic stress in maize leaves. Gene 555: 178-185.

12. Terao T, Yamashita A, Katoh S (1985) Chlorophyll b-deficient mutants of rice: $i$. absorption and fluorescence spectra and chlorophyll a/b ratios. Plant \& Cell Physiology 26: 1361-1367.

13. Staehelin LA, TG Fallbel (1994) Characterization of a family of chlorophyll-deficient wheat (triticum) and barley (hordeum vulgare) mutants with defects in the magnesium-insertion step of chlorophyll biosynthesis. Plant Physiol 104: 639-648.

14. Metz JG, Miles D (1982) Use of a nuclear mutant of maize to identity components of photosystem ii. Bba Bioenergetics 681: 95-102.

15. Falbel TG, Staehelin LA (2008) Partial blocks in the early steps of the chlorophyll synthesis pathway: a common feature of chlorophyll b-deficient mutants. Physiologia Plantarum 97: 311-320.

16. Oster U, Tanaka R, Tanaka A, et al. (2000) Cloning and functional expression of the gene encoding the key enzyme for chlorophyl b biosynthesis (cao) from arabidopsis thaliana. Plant Journal 21: 305-310.

17. Kendrick RE, MJ Terry (1999) Feedback inhibition of chlorophyl synthesis in the phytochrome chromophore-deficient aurea and yellow-green-2 mutants of tomato. Plant Physiol 119: 143-152.

18. Martin Müller, Muth JR, Gallusci P, et al. (1995) Regulation of storage protein synthesis in cereal seeds: developmental and nutritional aspects. Journal of Plant Physiol 145: 606-613.

19. Granick S (1948) Magnesium protoporphyrin ix as a precursor of chlorophyll in chlorella. Journal of Biological Chemistry 175: 333-342.

20. Granick S (1948) Protoporphyrin 9 as a precursor of chlorophyll. Journal of Biological Chemistry 172: 717-727.

21. Nagata M (2005) Inflammatory cells and oxygen radicals. Curr Drug Targets Inflamm Allergy 4: 503-504.

22. Coschigano KT, Melo-Oliveira R, J Lim, et al. (1948) Arabidopsis gls mutants and distinct fd-gogat genes: implications for photorespiration and primary nitrogen assimilation. Plant Cell 10: 741-752.

23. Gan S, Amasino RM (1995) Inhibition of leaf senescence by autoregulated production of cytokinin. Science 270: 1986-1988.

24. Asada K, M Takahashi (1987) Production and scavenging of active oxygen photosynthesis. Elsevier science publishers, Amsterdam, 227-287.

25. Graham N, Simon D, Larissa N, et al. (2002) Drought and oxidative load in the leaves of c3 plants: A predominant role for photorespiration. Ann Bot 7: 841-850.

26. Foyer CH, Lelandais M, Kunert KJ (1994) Special review: Photooxidative stress in plants superoxide, active oxygen, uv-b irradiation, ascorbate, glutathione, stress tolerance. - Physiologia Plantarum.
27. Asada K (1999) The water-water cycle in chloroplasts: Scavenging of active oxygens and dissipation of excess photons. Annu Rev Plant Physiol Plant Mol Biol 50: 601-639.

28. Mullineaux $P$, Karpinski S (2002) Signal transduction in response to excess light: Getting out of the chloroplast. Curr Opin Plant Biol 5: 43-48.

29. Schnettger B, Critchley C, Santore UJ, et al. (1994) Relationship between photoinhibition of photosynthesis, $\mathrm{d} 1$ protein turnover and chloroplast structure: effects of protein synthesis inhibitors. Plant Cell and Environment 17: 55-64.

30. Niyogi KK (1999) Photoprotection Revisited: Genetic and Molecular Approaches. Annual Review of Plant Physiology and Plant Molecular Biology 5: 333-359.

31. Miyake C, Yokota A (2001) Cyclic flow of electrons within psll in thylakoid membranes. Plant and Cell Physiology 42: 508-515.

32. Carsten K, Jon A, Stefan J (2002) Rapid regulation of light harvesting and plant fitness in the field. Science 297: 91-93.

33. Adams BD, Gilmore AM, William WA (1996) In vivo functions of carotenoids in higher plants. Faseb 10: 403-412.

34. Frank HA, Cogdell RJ (1996) Carotenoids in photosynthesis. Photochemistry and Photobiology 63: 257-264.

35. Nicholas Smirnoff (1996) The function and metabolism of ascorbic acid in plants. Annals of Botany 78: 661-699.

36. Andrews JR, Fryer MJ, Baker NR (1995) Consequences of Ihc II deficiency for photosynthetic regulation in chlorine mutants of barley. Photosynth Res 44: 81-91.

37. Terao T, Sonoike K, Yamazaki JY, et al. (1996) Stoichiometries of photosystem $\mathrm{i}$ and photosystem ii in rice mutants differently deficient in chlorophyll b. Plant \& Cell Physiology 37: 299-306.

38. Demmig-Adams B, Adams WW (2006) Photoprotection in an ecological context: The remarkable complexity of thermal energy dissipation. New Phytol 172: 11-21.

39. Li XP, Olle B, Shih C, et al. (2000) A pigment-binding protein essential for regulation of photosynthetic light harvesting. Nature 403: 391-395.

40. Grieco M, Tikkanen M, Paakkarinen V, et al. (2012) Steady-state phosphorylation of light-harvesting complex ii proteins preserves photosystem $\mathrm{i}$ under fluctuating white light. Plant Physiol 160: 1896-1910.

41. Evans JR, Santiago LS (2014) Prometheuswiki gold leaf protocol: Gas exchange using LI-COR 6400. Funct Plant Biol 41: 223-226.

42. Trebitsh T, Goldschmidt EE, Riov J (1993) Ethylene induces de novo synthesis of chlorophyllase, a chlorophyll degrading enzyme, in citrus fruit peel. Proc Nati Acad Sci 90: 9441-9445.

43. Ries SK, CN Giannoplitis (1977) Superoxide dismutases: II. purification and quantitative relationship with water-soluble protein in seedlings. Plant Physiol 59: 315-318.

44. Anderson MD, Stewart CR, Prasad TK (1995) Changes in isozyme profiles of catalase, peroxidase, and glutathione reductase during acclimation to chilling in mesocotyls of maize seedlings. Plant Physiol 109: 1247-1257.

45. Cakmak I, Marschner H (1992) Magnesium deficiency and high light intensity enhance activities of superoxide dismutase, ascorbate peroxidase, and glutathione reductase in bean leaves. Plant Physiol 98: 1222-1227.

46. Long SP, Marshall-Colon A, Zhu XG (2015) Meeting the global 
Citation: Mo-zhen C, Hao-nan Q, Fu-lei M, et al. (2020) The Chlorophyll Biosynthesis and Degradation and Chloroplast Structure in Tomato Yellow Mutant. J Hortic Sci Res 3(1):113-124

food demand of the future by engineering crop photosynthesis and yield potential. Cell 161: 56-66.

47. Karl Pearson (1904) Mendel's Law. Nature 70: 626-627.

48. Marek Z, Marian B, Lenka B, et al. (2019) Phenotyping of isogenic chlorophyll-less bread and durum wheat mutant lines in relation to photoprotection and photosynthetic capacity. Photosynth Res 139: 239-251.

49. Tyutereva EV, Voitsekhovskaja OV (2011) Responses of chlorophyll b-free chlorine 3613 barley mutant to a prolonged decrease in illuminance: 1 dynamics of chlorophyll content, growth, and productivity. Russian Journal of Plant Physiology 58: 1-8.

50. Ort Donald R, Melis Anastasios (2011) Optimizing antenna size to maximize photosynthetic efficiency. Plant Physiology 155: 79-85.

51. Zhu XG, Long SP, Ort DR (2010) Improving photosynthetic efficiency for greater yield. Annu Rev Plant Biol 61: 235-261.

52. Song Q, Wang Y, Qu M, et al. (2017) The impact of modifying photosystem antenna size on canopy photosynthetic efficiency. Plant, Cell \& Environment.

53. Lin D, Q Jiang, K Zheng, et al. (2015) Mutation of the rice ASL2 gene encoding plastid ribosomal protein $\mathrm{L} 21$ causes chloroplast developmental defects and seedling death. Plant Biol 17: 599607.

54. Tuba Z, Lichtenthaler HK, Maroti I, et al. (1993) Resynthesis of thylakoids and functional chloroplasts in the desiccated leaves of the poikilochlorophyllous plant xerophytascabrida upon rehydration. Journal of Plant Physiology 142: 742-748.

55. Casal JJ, Whitelam GC, Smith H (1990) Phytochrome effects on the relationship between chlorophyll and steady-state levels of thylakoid polypeptides in light-grown tobacco. Plant Physiology 94: 370-374.

56. Rebeiz CA (2002) Analysis of intermediates and end products of the chlorophyll biosynthetic pathway. Heme, Chlorophyll, and Bilins, Humana Press, 111-155.

57. Chatterjee A, Kundu S (2015) Revisiting the chlorophyll biosynthesis pathway using genome scale metabolic model of oryza sativa japonica. Sci Rep 5: 14975.

58. Anderson IC, Robertson DS (1960) Role of carotenoids in protecting chlorophyll from photodestruction. Plant Physiol 35: 531-534.

59. Genty B, Briantais JM, Baker NR (1989) The relationship between the quantum yield of photosynthetic electron transport and quenching of chlorophyll fluorescence. Biochimica et Biophysica Acta General Subjects 990: 87-92.

60. Tomio T, Sakae K (1996) Antenna sizes of photosystem I and photosystem II in chlorophyll b-deficient mutants of rice. evidence for an antenna function of photosystem ii centers that are inactive in electron transport. Plant \& Cell Physiology 37: 307-312.

\section{Supplementary Tables:}

Table S1: Changes in pigment content $\left(\mathrm{mg} \cdot \mathrm{L}^{-1}\right)$ during different developmental periods.

\begin{tabular}{|l|l|l|l|l|}
\hline \multicolumn{1}{|c|}{ Time points } & \multicolumn{1}{c|}{ 9d } & \multicolumn{1}{c|}{ 12d } & \multicolumn{1}{c|}{ 15d } & \multicolumn{1}{c|}{ 60d } \\
\hline$y m C_{a} / C_{b}$ & $2.867 \pm 0.03^{\mathrm{a}}$ & $2.984 \pm 0.02^{\mathrm{a}}$ & $3.214 \pm 0.05^{\mathrm{a}}$ & $3.943 \pm 0.23^{\mathrm{a}}$ \\
\hline$y m C_{\mathrm{c}}$ & $8.604 \pm 0.13^{\mathrm{a}}$ & $9.048 \pm 0.32^{\mathrm{a}}$ & $3.717 \pm 0.02^{\mathrm{b}}$ & $2.08 \pm 0.43^{\mathrm{a}}$ \\
\hline$z s 4 C_{\mathrm{a}} / C_{\mathrm{b}}$ & $2.81 \pm 0.77^{\mathrm{a}}$ & $2.823 \pm 0.04^{\mathrm{a}}$ & $2.692 \pm 0.09^{\mathrm{b}}$ & $2.20 \pm 0.66^{\mathrm{a}}$ \\
\hline$z s 4 C_{c}$ & $9.829 \pm 0.02^{\mathrm{a}}$ & $9.421 \pm 0.03^{\mathrm{a}}$ & $9.441 \pm 0.21^{\mathrm{a}}$ & $5.645 \pm 0.34^{\mathrm{a}}$ \\
\hline
\end{tabular}

Data are presented as means $(n=3)$. Different lowercase letters $(a, b, c)$ indicate statistically significant differences $(P<0.05)$ between treatments in the same phenotype using $L S D$ tests.

Note: $C_{a}$ : Chlorophyll a content, $C_{b}$ : Chlorophyll b content, $C_{c}$ : Total chlorophyll content.

Table S2: Chlorophyll and $\mathrm{C}_{\mathrm{c}}$ content $\left(\mathrm{mg} \cdot \mathrm{L}^{-1}\right)$.

\begin{tabular}{|l|l|l|}
\hline \multicolumn{1}{|c|}{ Material } & pigment content $\mathbf{C}_{\mathrm{a}} / \mathbf{C}_{\mathrm{b}}\left(\mathbf{m g} \cdot \mathrm{L}^{-\mathbf{1}}\right)$ & pigment content $\mathbf{C}_{\mathrm{c}}\left(\mathbf{m g} \cdot \mathrm{L}^{-1}\right)$ \\
\hline$y m$ & $3.869 \pm 0.09^{\mathrm{a}}$ & $2.537 \pm 0.01^{\mathrm{b}}$ \\
\hline$z s 4$ & $2.135 \pm 0.39^{c}$ & $7.623 \pm 0.54^{\mathrm{a}}$ \\
\hline
\end{tabular}

Data are presented as means $(n=3)$. Different lowercase letters $(a, b)$ indicate statistically significant differences $(P<0.05)$ between treatments in the same phenotype using $L S D$ tests.

Note: $C_{a}$ : Chlorophyll a content, $C_{b}$ : Chlorophyll b content, $C_{c}$ : Total chlorophyll content.

DOI: $10.36959 / 745 / 406$

Copyright: (C) 2020 Patel VB, et al. This is an open-access article distributed under the terms of the Creative Commons Attribution License, which permits unrestricted use, distribution, and reproduction in any medium, provided the original author and source are credited. 